\title{
Biochemical and structural characterization of a thermostable $\beta$-glucosidase from Halothermothrix orenii for galacto-oligosaccharide synthesis
}

\author{
Noor Hassan • Thu-Ha Nguyen • Montira Intanon • \\ Lokesh D. Kori • Bharat K. C. Patel • Dietmar Haltrich • \\ Christina Divne $\cdot$ Tien Chye Tan
}

Received: 21 May 2014 / Revised: 4 August 2014 / Accepted: 5 August 2014 /Published online: 31 August 2014

(C) The Author(s) 2014. This article is published with open access at Springerlink.com

\begin{abstract}
Lactose is a major disaccharide by-product from the dairy industries, and production of whey alone amounts to about 200 million tons globally each year. Thus, it is of particular interest to identify improved enzymatic processes for lactose utilization. Microbial $\beta$-glucosidases (BGL) with significant $\beta$-galactosidase (BGAL) activity can be used to convert lactose to glucose (Glc) and galactose (Gal), and most retaining BGLs also synthesize more complex sugars from the monosaccharides by transglycosylation, such as galactooligosaccharides (GOS), which are prebiotic compounds that stimulate growth of beneficial gut bacteria. In this work, a
\end{abstract}

Noor Hassan and Thu-Ha Nguyen are Joint first authorship

Electronic supplementary material The online version of this article (doi:10.1007/s00253-014-6015-x) contains supplementary material, which is available to authorized users.

N. Hassan • C. Divne • T. C. Tan $(\bowtie)$

KTH Royal Institute of Technology, School of Biotechnology,

Albanova University Center, Roslagstullsbacken 21,

S-10691 Stockholm, Sweden

e-mail: tantc@kth.se

T.-H. Nguyen $\cdot$ M. Intanon $\cdot$ D. Haltrich

Food Biotechnology Laboratory, BOKU University of Natural

Resources and Life Sciences, A-1190 Vienna, Austria

L. D. Kori • B. K. C. Patel

Microbial Gene Research and Resources Facility, Griffith University,

School of Biomolecular and Physical Sciences, Brisbane, QLD 4111,

Australia

L. D. Kori

Biochemistry and Molecular Biology, Baylor College of Medicine,

Houston, TX 77030, USA

C. Divne $\cdot$ T. C. Tan

Department of Medical Biochemistry and Biophysics,

Scheelelaboratoriet, Karolinska Institute, Scheeles väg 2,

S-17177 Stockholm, Sweden
BGL from the thermophilic and halophilic bacterium Halothermothrix orenii, HoBGLA, was characterized biochemically and structurally. It is an unspecific $\beta$-glucosidase with mixed activities for different substrates and prominent activity with various galactosidases such as lactose. We show that $H o B G L A$ is an attractive candidate for industrial lactose conversion based on its high activity and stability within a broad $\mathrm{pH}$ range (4.5-7.5), with maximal $\beta$-galactosidase activity at $\mathrm{pH}$ 6.0. The temperature optimum is in the range of 65-70 ${ }^{\circ} \mathrm{C}$, and $\mathrm{HoBGLA}$ also shows excellent thermostability at this temperature range. The main GOS products from $\mathrm{Ho}^{-}$ BGLA transgalactosylation are $\beta$-D-Gal $p$ - $(1 \rightarrow 6)$-D-Lac $(6 \mathrm{GALA})$ and $\beta$-D-Gal $p-(1 \rightarrow 3)$-D-Lac (3GALA), indicating that D-lactose is a better galactosyl acceptor than either of the monosaccharides. To evaluate ligand binding and guide GOS modeling, crystal structures of HoBGLA were determined in complex with thiocellobiose, 2-deoxy-2-fluoro-D-glucose and glucose. The two major GOS products, 3GALA and 6GALA, were modeled in the substrate-binding cleft of wild-type $\mathrm{Ho}$ BGLA and shown to be favorably accommodated.

Keywords $\beta$-glucosidase $\beta$-galactosidase .

Halothermophile $\cdot$ Halothermothrix $\cdot$ Lactose conversion . Galacto-oligosaccharides · Biochemical characterization · Structural analysis

\section{Introduction}

Lactose generated as by-product from liquid whey alone amounts to an impressive 150-200 million tons per year (Smithers 2008). Thus, lactose constitutes a vast carbohydrate resource for industrial enzymatic processes towards valueadded products with the aim to promote sustainable development. One important application of lactose conversion is the 
production of compounds such as galacto-oligosaccharides (GOS). GOS have been recognized as prebiotic compounds that stimulate growth of certain members of the gut microbiota associated with beneficial effects. Production of GOS from lactose can be achieved by different approaches: (i) transglycosylation activity by glycoside hydrolases (GHs), which is the method currently employed by industry for production of GOS from lactose, with the yield of the reaction depending on the relative ratio of the transglycosylation versus hydrolysis reaction; (ii) acid hydrolysis of lactose, which produces a complex mixture of disaccharides and trisaccharides with a variety of linkages and anomeric configurations; however, this latter approach results in glycoside preparations that are non-applicable to the food industry since they do not meet the EC food regulations (De Roode et al. 2003); (iii) the use of glycosyltransferases to synthesize the sugar compounds of interest. Glycosyltransferases use activated sugar nucleotide donors where the sugar is transferred to a specific acceptor. Although the reactions are highly stereoselective and regioselective to give defined products compared with the use of glycoside hydrolases and chemical acid hydrolysis, the method is costly since the cost of enzyme production is high and the sugar nucleotide donors are expensive.

Based on the advantages and disadvantages of the different approaches mentioned above, the use of GHs is preferred from the perspective of purpose and cost, at least when GOS production for the food industry is considered. However, the yield of GOS formed by GHs through transglycosylation is an issue and needs to be addressed in each individual case, i.e., depending on the enzyme(s) and reaction conditions used. There are strategies for improving GOS yields, such as selecting an enzyme with high inherent transglycosylation activity. Although examples of engineered GH mutants with increased transglycosylation activity have been reported (Jørgensen et al. 2001; Placier et al. 2009; Wu et al. 2013), the mechanism behind the altered reaction patterns is not understood. Other parameters that affect GOS yields include reaction temperature and lactose concentration. Due to the increased solubility of lactose at higher temperatures and the decrease in water available to act as acceptor, the GOS yield typically increases with increasing temperature (Vera et al. 2012). High temperature is also desirable to limit microbial contamination of the substrate solutions (Urrutia et al. 2013). As found by many other authors, the lactose concentration has a significant impact on the final GOS yield (Splechtna et al. 2006).

Restrictions on the temperatures that can be used will ultimately depend on the stability and activity profile of the enzyme catalyst, as well as the degree of side reactions in the reaction mixture, such as the Maillard reaction, i.e., glycosylation of mainly protein lysine side chains by reducing sugars. Bruins and coworkers reported that at temperatures above $80{ }^{\circ} \mathrm{C}$, enzyme inactivation is doubled in the presence, as opposed to absence, of sugar (Bruins et al. 2003). Although this may not be an issue in batch-reaction mode, enzyme inactivation is likely to be more pronounced in a continuous system that operates over an extended time scale.

Based on the above considerations, enzymes that evolved naturally to tolerate high temperatures and concentrations of reaction substrates and products are of particular interest for industrial GOS production. Retaining BGALs used in the dairy industry are typically enzymes of fungal origin belonging to the GH2 family of glycoside hydrolases (http://www. cazy.org; Cantarel et al. 2009). As an alternative to BGALs, microbial $\beta$-glucosidases (BGLs; EC 3.2.1.21) can be used for the purpose of lactose conversion and GOS synthesis, as well as other biotechnological applications (Bhatia et al. 2002; Park et al. 2005). Unlike the BGALs of the GH2 family, most BGLs belonging to the GH1 family of glycoside hydrolases (http://www.cazy.org; Cantarel et al. 2009) are monomeric, small $(50 \mathrm{kDa})$, and stable $(\alpha / \beta)_{8}$-barrel scaffolds where the functional catalytic property is built on a single polypeptide chain, thus making protein production easier and less costly. Moreover, GH1 BGLs typically display high $\beta$-galactosidase (BGAL) and transglycosylation activities. Another advantage of microbial BGLs in a biotechnological context is the broad specificity towards galactosidases, fucosidases, and xylosidases and the cleavage of $\beta(1 \rightarrow$ $1), \beta(1 \rightarrow 2), \beta(1 \rightarrow 4)$, and $\beta(1 \rightarrow 6)$ glycosidic bonds.

In the search of enzymes for lactose conversion and GOS production, it is of particular interest to screen genomes of thermophilic and hyperthermophilic bacteria for new enzyme candidates. Halothermothrix orenii is a heterotrophic, halophilic, thermophilic, and obligate anaerobic bacterium. The bacterium was originally isolated from a Tunisian hypersaline lake (Cayol et al. 1994), a habitat which is subjected to seasonal changes in temperatures and salinity. Indeed, bioinformatics analysis of the $H$. orenii genome revealed a full inventory of genes encoding GHs (Mijts and Patel 2001; Mavromatis et al. 2009), of which one gene coding for a GH1 $\beta$-D-glucosidase showed up as particularly interesting. The gene product was named $H o B G L A$, and a preliminary structural X-ray characterization was performed at $3.0 \AA$ resolution (Kori et al. 2011). However, the crystals of this enzyme variant were of poor quality and not useful for further crystal-structure analysis of ligand complexes and rational enzyme design.

Here, we report the biochemical characterization and highresolution structure analysis of wild-type HoBGLA. We address specifically the enzyme's catalytic performance for use in lactose conversion and GOS production, and show that the enzyme displays very promising characteristics for this application. The biochemical results are discussed with reference to the structural framework of HoBGLA based on the new highresolution crystal structures of wild-type HoBGLA expressed with a cleavable hexahistidine tag. Additionally, the crystal 
structures of three complexes of wild-type HoBGLA are reported: a covalent HoBGLA nucleophile (Glu354) complex with 2-deoxy-2-fluoro-D-glucose at $2.0 \AA$ resolution; HoBGLA in complex with thiocellobiose at $1.85 \AA$ resolution; and a HoBGLA complex with D-glucose (Glc) at $1.80 \AA$ resolution. To confirm the identity of the catalytic residues, activity data using catalytically compromised active-site mutants are included in our analysis, i.e., variants where the acid/ base catalyst (Glu166) and the nucleophile (Glu354), as well as a crucial substrate-binding side chain (Glu408) have been replaced by isosteric glutamine side chains.

\section{Materials and methods}

Cloning, expression, and purification of wild-type HoBGLA

The cloning of the $H$. orenii bglA gene $(1.35 \mathrm{kbp})$ coding for 451 amino acids (UniProtKB B8CYA8) into the expression vector pET22b $(+)$ carrying a non-cleavable C-terminal hexahistidine tag has been reported previously (Kori et al. 2011). Since the expressed protein from this gene construct resulted in poorly diffracting protein crystals (maximum $3.0 \AA$ resolution), the same $b g l A$ gene was also cloned into an alternative Escherichia coli expression vector. The bglA gene was amplified by standard PCR and cloned into the pNIC28Bsa4 vector under the control of T7 promoter (Savitsky et al. 2010) using ligation-independent cloning (Doyle 2005). The vector adds a cleavable hexahistidine tag and the Tobacco Etch virus (TEV) protease cleavage site at the N-terminus of the expressed protein with the sequence ${ }^{-23}$ MHHHHHHSS GVDLGTENLYFQSM $^{-1}$, which allows for the tag to be removed proteolytically using TEV protease. The recombinant plasmid expressing His $_{6}$-TEV-bglA was initially transformed into $E$. coli Mach1 ${ }^{\mathrm{TM}}$ (Invitrogen) and grown on Luria Bertani (LB) agar plates supplemented with $5 \%$ sucrose and $50 \mu \mathrm{g} / \mathrm{mL}$ kanamycin for the selection of recombinant plasmids with cleaved SacB (levansucrase).

The recombinant plasmid was isolated from $E$. coli Mach1 ${ }^{\mathrm{TM}}$ cells using plasmid preparation QIAprep ${ }^{\circledR}$ Spin Miniprep Kit (Qiagen), followed by transformation into the E. coli expression strain BL21(DE3). Transformed BL21(DE3) cells were grown in 0.6 L Terrific Broth (TB) medium supplemented with $50 \mu \mathrm{g} / \mathrm{mL}$ kanamycin and $60 \mathrm{~mL}$ glycerol (per $600 \mathrm{~mL}$ ), inoculated with $7 \mathrm{~mL}$ overnight seed culture of transformed BL21 (DE3), and allowed to grow at $37^{\circ} \mathrm{C}$ with constant shaking at $200 \mathrm{rpm}$. At an optical density (OD) at $600 \mathrm{~nm}$ of $0.7, \mathrm{bglA}$ expression was induced with $0.2 \mathrm{mM} \beta$-D-1-thiogalactopyranoside (IPTG) and the culture was left to grow at $18^{\circ} \mathrm{C}$ for 16 to $18 \mathrm{~h}$. Cells were harvested by centrifugation at $4{ }^{\circ} \mathrm{C}(8983 r c f)$ using an Avanti J-20 XP centrifuge (Beckman) with rotor JLA 8.1000 for $15 \mathrm{~min}$. The bacterial cell pellet was resuspended in three volumes of lysis buffer [20 mM 4-(2-hydroxyethyl)-1-piperazine ethanesulfonic acid (HEPES) pH 7.0, $150 \mathrm{mM} \mathrm{NaCl}$. The sample was homogenized using an AVESTIN Emulsiflex-C3 system, and the lysate was collected in a beaker on ice. The lysate was centrifuged at $4{ }^{\circ} \mathrm{C},(39191 r c f)$ using an Avanti J$20 \mathrm{XP}$ centrifuge (Beckman) with rotor JA 25.50 for $30 \mathrm{~min}$ to pellet the cell debris.

The gene product resulting from expression of pNIC28Bsa4-bglA is hereafter denoted HoBGLA, and the gene product expressed from the pET22b(+) vector as HoBGLA ${ }_{P E T}$ A 2 - $\mathrm{mL} \mathrm{Ni}^{2+}$-charged immobilized metal affinity chromatography (IMAC) Ni-NTA agarose resin (Invitrogen) was washed and equilibrated with lysis buffer. Clear lysate containing HoBGLA was loaded onto the column, followed by a washing step with five column volumes (CVs) of wash buffer $(20 \mathrm{mM}$ HEPES pH 7.0, $150 \mathrm{mM} \mathrm{NaCl}$, and $20 \mathrm{mM}$ imidzaole). HoBGLA was eluted with elution buffer (20 mM HEPES pH 7.0, $150 \mathrm{mM} \mathrm{NaCl}$, and $350 \mathrm{mM}$ imidazole). To cleave off the hexahistidine tag and remove the imidazole, the protein sample was treated with TEV protease at 1:50 ratio, placed in a dialysis bag with molecular weight cut off (MWCO) 12$14 \mathrm{kDa}$, which was incubated in a beaker containing dialysis buffer (20 mM HEPES pH 7.0 and $150 \mathrm{mM} \mathrm{NaCl}$ ) at $4{ }^{\circ} \mathrm{C}$ overnight. Following TEV protease treatment, HoBGLA was subjected to a second round of $\mathrm{Ni}^{2+}$-IMAC purification. The flow-through containing the TEV-treated protein was collected.

The protein sample was concentrated to $35 \mathrm{mg} / \mathrm{mL}$ using a Vivaspin ${ }^{\circledR}$ centrifugal concentrator (MWCO $10 \mathrm{kDa}$ ). To remove any $\mathrm{Ni}^{2+}$ contamination from the previous IMAC steps, EDTA was added to a final concentration of $10 \mathrm{mM}$ before the sample was further purified by size-exclusion chromatography using a HiLoad ${ }^{\mathrm{TM}}$ 16/60 Superdex $^{\mathrm{TM}} 200$ prep grade column (GE Healthcare Life Sciences) equilibrated with $20 \mathrm{mM}$ HEPES ( $\mathrm{pH}$ 7.0) and $150 \mathrm{mM} \mathrm{NaCl}$. Proteincontaining fractions $(1 \mathrm{~mL})$ were collected. Suitably pooled fractions were concentrated to $50 \mathrm{mg} / \mathrm{mL}$ and used for subsequent crystallization experiments. The purity of $H o B G L A$ was assessed by SDS-PAGE.

Production of catalytically impaired mutants of HoBGLA

To generate HoBGLA mutants E166Q, E354Q, and E408Q, the HoBGLA gene from the vector pNIC28-Bsa4-bglA was used as template and subjected to site-directed mutagenesis using PCR with the primers $H o$ BGLA E166Q fwd (5'-TGGA CCTCTGGGTTACCCATAATCAGCCCTGGGTAGTT-3') and HoBGLA E166Q rev (5'-AACTACCCAGGGCTGATT ATGGGTAA C C CAGA GGTCCA-3'), Ho B GLA E408Q fwd (5'-GGTTATTATGTGTGGTCATTGATGGA TAATTTTCAGTGGGCC TATGGCTATAG-3'), and HoBGLA E408Q rev (5'-CTATAGCCATAGGCCCACTGAA AATTATCCA TCAATGACCACACATAATAACC-3'), as 
well as HoBGLA E354Q fwd (5'-CCGATAAGCCCCTTTA CATAACACAGAACGGGGCAGCTTTT- ${ }^{\prime}$ ) and HoBGLA E354Q rev (5'-AAAAGCTGCCCCGTTCTGTGTTATGT AAAGGGGCTTATCGG-3'), respectively. These primers were designed using the QuickChange ${ }^{\circledR}$ Primer Design Program from Agilent Technology.

The PCR reaction contained $0.5 \mathrm{U}$ Pfu DNA polymerase (Fermentas, Germany), $70 \mathrm{ng}$ of plasmid DNA, $0.4 \mu \mathrm{L}$ primer pair (45 ng/ $\mu \mathrm{L}), 10 \mu \mathrm{M}$ of dNTP mix, $1 \mu \mathrm{L}$ DMSO, $24 \mu \mathrm{L}$ $\mathrm{H}_{2} \mathrm{O}$, and $2.5 \mu \mathrm{L}$ Pfu Ultra II Fusion buffer in a total volume of $25 \mu \mathrm{L}$. The following conditions were used for mutagenic PCRs: 30 cycles of $95^{\circ} \mathrm{C}, 3 \mathrm{~min} ; 94^{\circ} \mathrm{C}, 30 \mathrm{~s} ; 65^{\circ} \mathrm{C}, 8 \mathrm{~min}$; and with a final incubation at $65^{\circ} \mathrm{C}$ for $10 \mathrm{~min}$. Following PCR, the methylated template-DNA was degraded by digestion with $1 \mu \mathrm{L} D p n \mathrm{I}(10 \mathrm{U})$ at $37{ }^{\circ} \mathrm{C}, 2 \mathrm{~h}$.

The DpnI-digested PCR products were initially transformed into the E. coli cloning strain Mach1 ${ }^{\mathrm{TM}}$ (Invitrogen) grown on Luria Bertani (LB) agar plates supplemented with $50 \mu \mathrm{g} / \mathrm{mL}$ kanamycin. Recombinant plasmids from Mach1 cells were isolated using the QIAprep ${ }^{\circledR}$ Spin Miniprep Kit (Qiagen), followed by plasmid transformation into the E. coli expression strain BL21 (DE3). The HoBGLA mutants E166Q, E354Q, and E408Q were expressed as for wild-type HoBGLA.

$\boldsymbol{\beta}$-galactosidase and $\boldsymbol{\beta}$-glucosidase activity assays with chromogenic substrates

When chromogenic $o$ NPGal ( $o$-nitrophenyl- $\beta$-Dgalactopyranoside) or $p$ NPGal ( $p$-nitrophenyl- $\beta$-Dgalactopyranoside) were used as substrates for $\mathrm{HoBGLA}$, the determination of $\beta$-galactosidase activity was carried out at $30{ }^{\circ} \mathrm{C}$ with $22 \mathrm{mM} o \mathrm{NPGal}$ or $p$ NPGal solutions in $20 \mathrm{mM}$ HEPES buffer containing $150 \mathrm{mM} \mathrm{NaCl}(\mathrm{pH} \mathrm{7.0)}$ ). The reaction was initiated by adding $20 \mu \mathrm{L}$ of enzyme solution to $480 \mu \mathrm{L}$ of the substrate solution, and then incubated for 10 min using an Eppendorf thermomixer compact (Hamburg, Germany). Agitation was at $600 \mathrm{rpm}$. The reaction was stopped by adding $750 \mu \mathrm{L}$ of $0.4 \mathrm{M} \mathrm{Na}_{2} \mathrm{CO}_{3}$. The release of $o$-nitrophenol ( $o \mathrm{NP})$ or $p$-nitrophenol $(p \mathrm{NP})$ was measured by determining the absorbance at $420 \mathrm{~nm}$. One unit of $o$ NPGal or $p$ NPGal activity was defined as the amount of enzyme releasing $1 \mu \mathrm{mol}$ of $o \mathrm{NP}$ or $p \mathrm{NP}$, respectively, per minute under the described conditions.

The $\beta$-glucosidase activity of $H o$ BGLA was measured using $o$ NPGlc ( $o$-nitrophenyl- $\beta$-D-glucopyranoside) or $p$ NPGlc ( $p$-nitrophenyl- $\beta$-D-glucopyranoside) as the substrates, in principle as described above for the $\beta$-galactosidase assay. One unit of $o$ NPGlc or $p$ NPGlc activity was defined as the amount of enzyme releasing $1 \mu \mathrm{mol}$ of $o \mathrm{NP}$ or $p \mathrm{NP}$, respectively, per minute under similar conditions as described for determination of $\beta$-galactosidase activity.
Activity assays for wild-type and mutant HoBGLA with cellobiose and lactose as substrates

For characterization of the hydrolytic activity of $\mathrm{HoBGLA}$ using cellobiose and lactose, the glucose oxidase (GOD) and horseradish peroxidase (POD) assays were used as described by Kunst and coworkers (Kunst et al. 1988). The assay solutions were prepared by adding GOD and POD to final concentrations of 2.41 and $1.45 \mathrm{U} / \mathrm{mL}$, respectively, to $200 \mathrm{~mL}$ solution of $4 \mathrm{mM} \mathrm{KH}_{2} \mathrm{PO}_{4}, 6.4 \mathrm{mM} 4$-aminoantipyrine, and $11 \mathrm{mM}$ phenol $\mathrm{pH}$ 7.0.

When lactose or cellobiose was used as substrate, $20 \mu \mathrm{L}$ enzyme solutions were added to $480 \mu \mathrm{L}$ of substrate solution in $20 \mathrm{mM}$ Bis-Tris buffer $\mathrm{pH}$ 7. The reaction mixtures were incubated at $50{ }^{\circ} \mathrm{C}$ using an Eppendorf heat block. After $5 \mathrm{~min}$, the reaction was stopped by heating the reaction mixture at $99^{\circ} \mathrm{C}$ for $3 \mathrm{~min}$ and the sample was centrifuged at 13,000 rpm for $1 \mathrm{~min}$ to pellet the protein precipitate. The sample was allowed to cool at room temperature, and the release of D-glucose was assessed colorimetrically by adding $60 \mu \mathrm{L}$ of reaction mixture to $600 \mu \mathrm{L}$ of the GOD/POD assay solution. The assay mixture $(660 \mu \mathrm{L})$ was incubated in the dark at room temperature for $40 \mathrm{~min}$, and the absorbance at $546 \mathrm{~nm}$ was measured. The amount of glucose produced was calculated from a glucose standard curve obtained by adding $60 \mu \mathrm{L}(0.28-3.89 \mathrm{mM})$ of standard glucose solutions to $600 \mu \mathrm{L}$ assay solution and incubated at room temperature in the dark for $40 \mathrm{~min}$. One unit of lactase activity was defined as the amount of enzyme releasing $1 \mu \mathrm{mol}$ of D-glucose per minute under the given conditions. One unit of cellobiose activity was defined as the amount of enzyme releasing $2 \mu \mathrm{mol}$ of D-glucose per minute under similar conditions as described for determination of $\beta$-galactosidase activity using lactose as the substrate.

\section{Kinetic measurements}

All steady-state kinetic measurements were performed at $65{ }^{\circ} \mathrm{C}$ using $o$ NPGal, $p$ NPGal, $o$ NPGlc, $p$ NPGlc, lactose, and cellobiose as substrates in $20 \mathrm{mM}$ HEPES buffer containing $150 \mathrm{mM} \mathrm{NaCl}(\mathrm{pH} \mathrm{7.0)}$ ) with the concentrations ranging from 0.5 to $20 \mathrm{mM}$ for $o \mathrm{NPGal}$ and $p$ NPGal, 0.1 to $15 \mathrm{mM}$ for $o$ NPGlc and $p$ NPGlc, 10 to $700 \mathrm{mM}$ for lactose, and 1 to $350 \mathrm{mM}$ for cellobiose, respectively. The kinetic parameters were calculated by nonlinear regression, and the observed data were fit to the Henri-Michaelis-Menten equation (SigmaPlot, SPSS Inc., Illinois, USA).

Temperature and $\mathrm{pH}$ profiles of the $\beta$-galactosidase activity of HoBGLA

The $\mathrm{pH}$ dependence of $H o$ BGLA activity was evaluated by the standard $\beta$-galactosidase assay with $22 \mathrm{mM} o \mathrm{NPGal}$ in the 
$\mathrm{pH}$ range from 4 to 10 using Briton-Robinson buffer $(20 \mathrm{mM}$ acetic acid, $20 \mathrm{mM}$ phosphoric acid, and $20 \mathrm{mM}$ boric acid titrated with $1 \mathrm{M} \mathrm{NaOH}$ to the desired $\mathrm{pH}$ ). The temperature optima for the hydrolysis activity of HoBGLA with both substrates lactose and $o$ NPGal were determined at $30-85^{\circ} \mathrm{C}$. The thermostability was evaluated by incubating the pure enzyme in $20 \mathrm{mM}$ HEPES and $150 \mathrm{mM} \mathrm{NaCl}(\mathrm{pH} 7.0)$ at 65 and $70{ }^{\circ} \mathrm{C}$. The residual activities were measured regularly with $o$ NPGal as substrate. When lactose was used as substrate, the assay was carried out as previously described (Nguyen et al. 2007) with some modifications. The reaction was done in $20 \mathrm{mM}$ HEPES buffer with $150 \mathrm{mM} \mathrm{NaCl}$ ( $\mathrm{pH} 7.0$ ) for $10 \mathrm{~min}$ at $30{ }^{\circ} \mathrm{C}$, after which the reaction was stopped. The release of D-glucose was determined using a D-glucose assay kit (Megazyme). One unit of lactase activity was defined as the amount of enzyme releasing $1 \mu \mathrm{mol}$ of D-glucose per minute under the given conditions.

Transgalactosylation of lactose and analysis of galacto-oligosaccharides

Lactose solutions $(200,300$, and $350 \mathrm{~g} / \mathrm{L})$ were prepared in $20 \mathrm{mM}$ HEPES and $150 \mathrm{mM} \mathrm{NaCl}(\mathrm{pH} 7.0)$ containing $1 \mathrm{mM}$ $\mathrm{MgCl}_{2}$. Transgalactosylation reactions were performed on a 2-mL scale at $70{ }^{\circ} \mathrm{C}$ using $300 \mathrm{rpm}$ agitation and $12 \mathrm{U}_{\mathrm{oNPGal}}$ $\mathrm{mL}$ final concentration of a homogenous preparation of $\mathrm{Ho}$ BGLA. Samples were withdrawn at specific time intervals and immediately transferred to $99{ }^{\circ} \mathrm{C}$ for $5 \mathrm{~min}$ to inactivate the enzyme. Samples were stored at $-18{ }^{\circ} \mathrm{C}$ for subsequent analysis.

The GOS mixtures were analyzed by thin layer chromatography (TLC) and high-performance anion exchange chromatography with pulsed amperometric detection (HPAECPAD). TLC was carried out using high-performance TLC silica plates (HPTLC Lichrospher silica gel $60 \mathrm{~F}_{254} \mathrm{~S}$, Merck). An appropriately diluted sample containing $\sim 20 \mathrm{~g} / \mathrm{L}$ sugar was applied to the plate $(1.0 \mu \mathrm{L})$ and eluted twice in ascending mode with an $n$-butanol/n-propanol/ethanol/water mixture $(2: 3: 3: 2)$. Thymol reagent was used for detection.

HPAEC-PAD analysis was carried out on a Dionex DX500 system consisting of a GP50 gradient pump, an ED 40 electrochemical detector with a gold working electrode and an $\mathrm{Ag} / \mathrm{AgCl}$ reference electrode, and Chromeleon version 6.5 (Dionex Corp., Sunnyvale, CA). All eluents were degassed by flushing with helium for $30 \mathrm{~min}$. Separations were performed at room temperature on a CarboPac PA-1 column $(4 \times$ $250 \mathrm{~mm}$ ) connected to a CarboPac PA-1 guard column (Dionex). Separation of D-glucose, D-galactose (Gal), lactose, and allolactose was carried out with an isocratic run (45 min) with $15 \mathrm{mM} \mathrm{NaOH}$ at $1.0 \mathrm{~mL} / \mathrm{min}$, followed by $25 \mathrm{~min}$ elution with $100 \mathrm{mM} \mathrm{NaOH}$. For separation of other GOS, eluent A $(100 \mathrm{mM} \mathrm{NaOH})$ and $\mathrm{B}(100 \mathrm{mM} \mathrm{NaOH}$ and $150 \mathrm{mM} \mathrm{NaAc})$ were mixed to form the following gradient: $98 \% \mathrm{~A}$ from 0 to
$10 \mathrm{~min}, 98$ to $52 \% \mathrm{~A}$ from 10 to $40 \mathrm{~min}$, and then $52 \% \mathrm{~A}$ for another $5 \mathrm{~min}$. The column was washed with $20 \% \mathrm{~B}$ for $10 \mathrm{~min}$ and re-equilibrated for $15 \mathrm{~min}$ with the starting conditions of the employed gradient. Individual GOS components were identified by comparison to authentic standard sugars.

Crystal-structure analysis of HoBGLA ligand complexes

A preliminary X-ray crystallographic analysis at low resolution $(3.0 \AA)$ has been reported earlier for wild-type $\mathrm{Ho}$ BGLA $_{P E T}$ (Protein Data Bank, PDB, code 3TA9; Kori et al. 2011). HoBGLA was concentrated to $50 \mathrm{mg} / \mathrm{mL}$ in a solution containing $20 \mathrm{mM}$ HEPES pH 7.0 and $150 \mathrm{mM} \mathrm{NaCl}$. Crystallization screening was performed using the sitting-drop vapor diffusion method in 96-well screening plates (Corning 3550 96-well sitting drop plate) and dispensed by a mosquito ${ }^{\circledR}$ Crystal robotics (TTP Labtech) with drop size of $300 \mathrm{~nL}$ and protein-to-reservoir ratios of 1:1, 1:2, and 2:1. Solutions were from the commercial screens PACT Suite (Qiagen), JCSG Suite (Qiagen), and Crystal Screen HT (Hampton Research). Initial screen hits were optimized using 24-well plates (INTELLI-PLATETM24, Art Robbins Instrument). Well-diffracting crystals were obtained in $0.1 \mathrm{M}$ sodium cacodylate in the $\mathrm{pH}$ range 5.5-6.5, polyethylene glycol (PEG) 3350 in the concentration range 25-30\% $(w / v)$, and in the presence of either $\mathrm{MgCl}_{2}, \mathrm{CsCl}_{2}$ or sodium acetate. $\mathrm{Ho}$ BGLA structures were determined in complex with the ligands thiocellobiose (TCB), (thiocellobiose, 2-deoxy-2fluoro-D-glucose (2FGlc; Sigma-Aldrich Co. LLC., USA; Cat. $\mathrm{N}^{\mathrm{o}}$. F5006-25 mg), and cellobionolactam. The ligand complexes of HoBGLA were produced by immersing the crystals briefly in reservoir solution containing the ligand at saturating concentration, followed by vitrification in liquid nitrogen.

Crystals of $H o B G L A$ were soaked in the presence of TCB, $2 F$ Glc, or cellobionolactam, an inhibitor of some glycoside hydrolases. In the case of the cellobionolactam-soaked crystal, the ligand was cleaved leaving only glucose (Glc) bound in the active site. We will hereafter refer to this complex as glucose rather than a cellobionolactam complex. The optimized crystallization conditions for the HoBGLA-ligand complexes were wild-type HoBGLA-thiocellobiose (TCB), $0.1 \mathrm{M}$ sodium cacodylate $\mathrm{pH} 6.5,0.1 \mathrm{M} \mathrm{CsCl}_{2}$, and $26 \% \mathrm{PEG}$ 3350; HoBGLA-2FGlc, $0.1 \mathrm{M}$ sodium cacodylate $\mathrm{pH} 6.5$, $0.17 \mathrm{M}$ sodium acetate, and $30 \%(w / v)$ PEG 3350; and $\mathrm{Ho}$ BGLA-Glc, 0.1 M sodium cacodylate $\mathrm{pH}$ 5.5, $0.3 \mathrm{M} \mathrm{MgCl}_{2}$, and $25 \%(w / v)$ PEG 3350. All crystals were grown at room temperature.

X-ray intensity data were collected at $100 \mathrm{~K}$ using synchrotron radiation at the following ESRF (Grenoble, France) beamlines: HoBGLA-TBC, ID23-2; HoBGLA-2FGlc and HoBGLA-Glc at ID14-4. All data processing and scaling were performed using the XDS package (Kabsch 1993). 
Structure determination was performed by molecular replacement with PHASER implemented in the PHENIX suite (Adams et al. 2010) using the previously deposited 3.0-Å

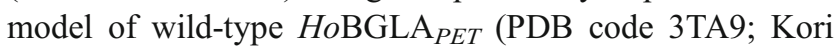
et al. 2011) as search model. Model building was performed using COOT (Emsley and Cowtan 2004) and O (Jones et al. 1991), and refinement using the PHENIX software package (Adams et al. 2010). Figures showing structural information were prepared with PyMOL (DeLano Scientific LLC, Palo Alto, CA, USA). Coordinates and structure factors are available in the Protein Data Bank database (http://www.rcsb.org) with the following PDB accession numbers: recombinant wild-type $H o$ BGLA-TCB, 4PTV; HoBGLA-2FGlc, 4PTW; and HoBGLA-Glc, 4PTX.

\section{Results}

Biochemical characterization of wild-type and mutant HoBGLA

HoBGLA was typically expressed in yields of $1.5 \mathrm{mg} / \mathrm{L}$ culture and purified to high homogeneity and monodispersity. The substrate specificity of purified HoBGLA was determined towards various aryl glycosides ( $o$ NPGal, $p$ NPGal, $o$ NPGlc, and $p$ NPGlc) and disaccharides (cellobiose and lactose), and kinetic constants were determined for these substrates (Table 1$)$. The apparent turnover values $\left(k_{\text {cat,app }}\right)$ were calculated using the experimentally determined $v_{\max }$ values and a molecular mass of $53 \mathrm{kDa}$ for the enzyme. The apparent catalytic efficiencies $\left(k_{\text {cat,app }} / K_{\mathrm{m}}\right)$ indicate that the glucopyranosides are better substrates than their galactopyranoside counterparts. This is mainly based on the lower Michaelis constant $K_{\mathrm{m}}$ for the glucose-containing substrates ( $o$ NPGlc, $p$ NPGlc, and cellobiose) as compared to the corresponding galactosecontaining molecules ( $o$ NPGal, $p$ NPGal, and lactose).

Aiming at a dairy application for this enzyme, $o$ NPGal and lactose were used as substrates to determine the optimal temperature and $\mathrm{pH}$ of $\mathrm{HoBGLA}$ activity. The $\mathrm{pH}$ optimum for the $\beta$-galactosidase activity was studied over a $\mathrm{pH}$ range of 4.0 to 10.0 and at $30^{\circ} \mathrm{C}$. Maximal $\beta$-galactosidase activity was obtained at pH 6.0 for both substrates. When $o$ NPGal was used as a substrate, $H o B G L A$ showed more than $80 \%$ of its maximum activity in the $\mathrm{pH}$ range of $\mathrm{pH}$ 5.0-7.0 (Fig. 1a), while when using lactose as a substrate, the enzyme showed more than $80 \%$ of its maximum activity in the $\mathrm{pH}$ range of $\mathrm{pH}$ 4.5-7.5. In the $\mathrm{pH}$ range tested $(\mathrm{pH} 4-10)$, the enzyme was inactivated at $\mathrm{pH}$ values above 8.0 (data not shown).

The temperature optimum for the $\beta$-galactosidase activity of $H$. orenii $H o$ BGLA was determined over the temperature range $30-85^{\circ} \mathrm{C}$. Maximal $\beta$-galactosidase activity was obtained at 65 and $75^{\circ} \mathrm{C}$ for $o \mathrm{NPGal}$ and lactose, with specific activity values of $304 \mathrm{U}_{\mathrm{oNPGa}} / \mathrm{mg}$ and $262 \mathrm{U}_{\mathrm{Lac}} / \mathrm{mg}$, respectively (Fig. 1b). The relative activity of $H o B G L A$ was higher for lactose than for $o \mathrm{NPGal}$ at temperatures above $75^{\circ} \mathrm{C}$. Furthermore, the enzyme retained $90 \%$ of its activity after $3 \mathrm{~h}$ of incubation at $65^{\circ} \mathrm{C}$ (Fig. S1). The enzyme showed halflife times of activity $\left(\tau_{1 / 2}\right)$ of 18 and $6 \mathrm{~h}$ at 65 and $70{ }^{\circ} \mathrm{C}$, respectively. We also investigated the effect of various metal ions on thermal stability of $H o B G L A \beta$-galactosidase activity, however, only $\mathrm{Mg}^{2+}$ produced a positive effect. When $1 \mathrm{mM} \mathrm{Mg}^{2+}$ was added, thermal stability of the enzyme as expressed by $\tau_{1 / 2}$ of $H o$ BGLA activity slightly increased to $24 \mathrm{~h}$ at $65^{\circ} \mathrm{C}$ and $9 \mathrm{~h}$ at $75^{\circ} \mathrm{C}$ (Fig. S1). The stabilizing effect of $\mathrm{Mg}^{2+}$ on the $\beta$-galactosidase activity of this $\beta$-glucosidase is in agreement with what we have observed previously for true $\beta$-galactosidases (Nguyen et al. 2006; Iqbal et al. 2011).

The kinetic constants for cellobiose and lactose as substrates are summarized in Table 1 for wild-type and mutant HoBGLA. As expected, the replacement of the catalytic nucleophile by a glutamine side chain (E354Q) results in a catalytically incompetent variant without detectable activity on either cellobiose or lactose. With cellobiose as substrate, replacing the acid/base catalyst by a glutamine (E166Q) does not alter the $K_{\mathrm{m}}$ value, but reduces the $k_{\text {cat,app }}$ value 54 -fold, giving a specificity constant, $k_{\text {cat,app }} / K_{\mathrm{m}}$, that is 59 -fold lower than for the wild type. With lactose as the substrate, the $K_{\mathrm{m}}$ value for E166Q improves slightly relative to the wild type (fourfold reduction), but at the expense of a 500-fold reduction in the $k_{\text {cat,app }}$ value, resulting in more than 100 -fold lower specificity constant value. Glu408 is proposed to participate in substrate binding, and replacement by a glutamine side chain has a little effect on $K_{\mathrm{m}}$ (1.3-fold reduction for both cellobiose and lactose), whereas $k_{\text {catapp }}$ is reduced 15 -fold for cellobiose and 3-fold for lactose.

\section{Galacto-oligosaccharide synthesis}

A spectrum of different galacto-oligosaccharides (GOS) was produced during conversion of lactose at $70{ }^{\circ} \mathrm{C}$ with an initial lactose concentration of $205 \mathrm{~g} / \mathrm{L}$ catalyzed by $\mathrm{HoBGLA}$ as analyzed by thin layer chromatography (TLC) (Fig. 2a). It was shown that lactose was cleaved and GOS was formed soon after the reaction was started. Subsequently, the influence of the initial lactose concentration on GOS production using $H o B G L A$ was investigated. For initial lactose concentrations of 200,300 , and $400 \mathrm{~g} / \mathrm{L}$, the maximum GOS yields were 51 , 112, and $185 \mathrm{~g} / \mathrm{L}$ (Fig. 2b), or approximately 30 , 41, and $50 \%$ (Fig. 2c). These amounts were obtained within 2 to $3 \mathrm{~h}$ of reaction at $91 \%$ lactose conversion.

Individual GOS can be separated effectively using a Carbopac PA1 column for HPAEC-PAD (Fig. S2). It was possible to identify the main products of the transgalactosylation reaction of $H o$ BGLA when lactose was the substrate (Fig. 2d). The predominant oligosaccharide 


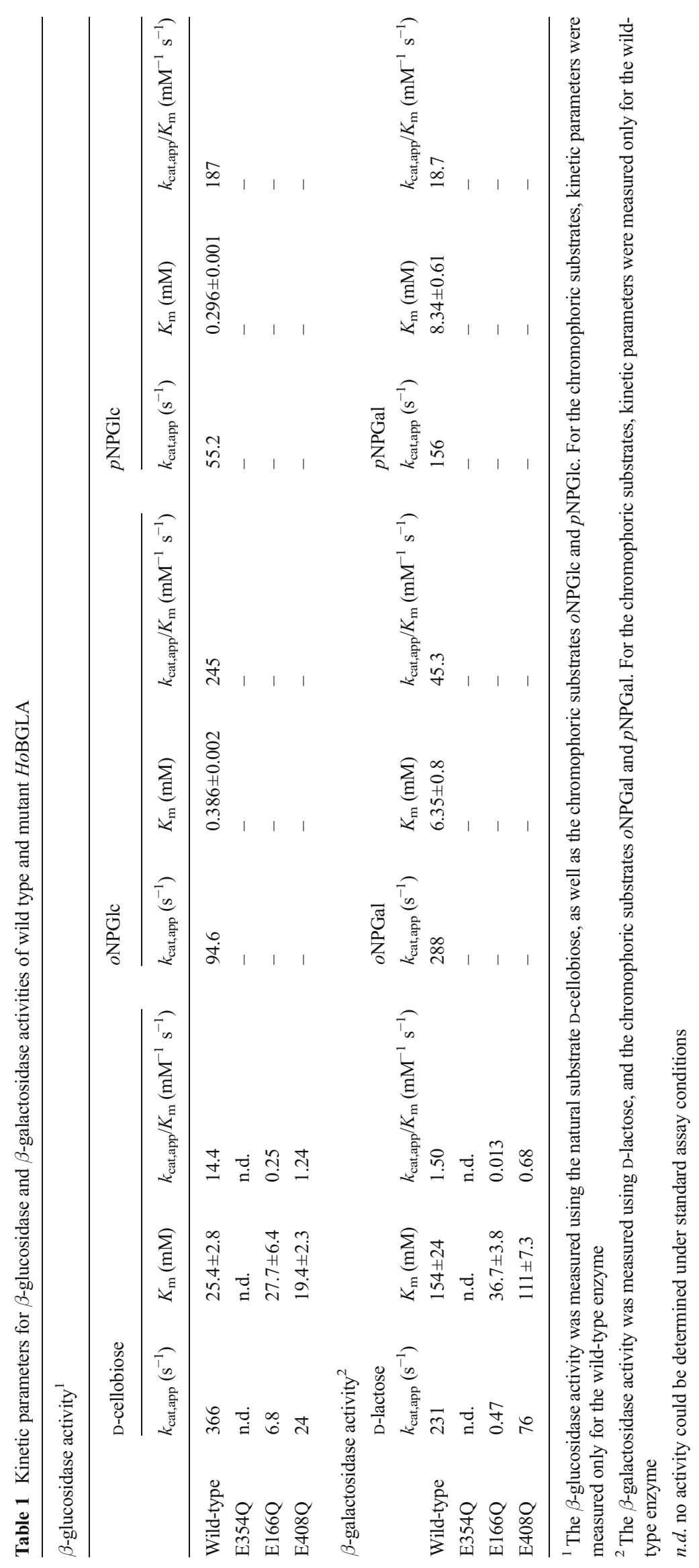


A

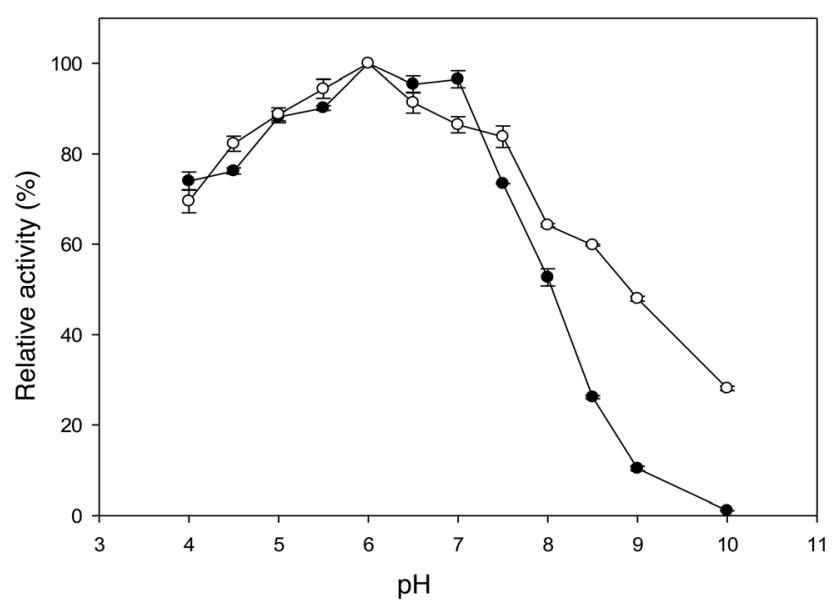

B

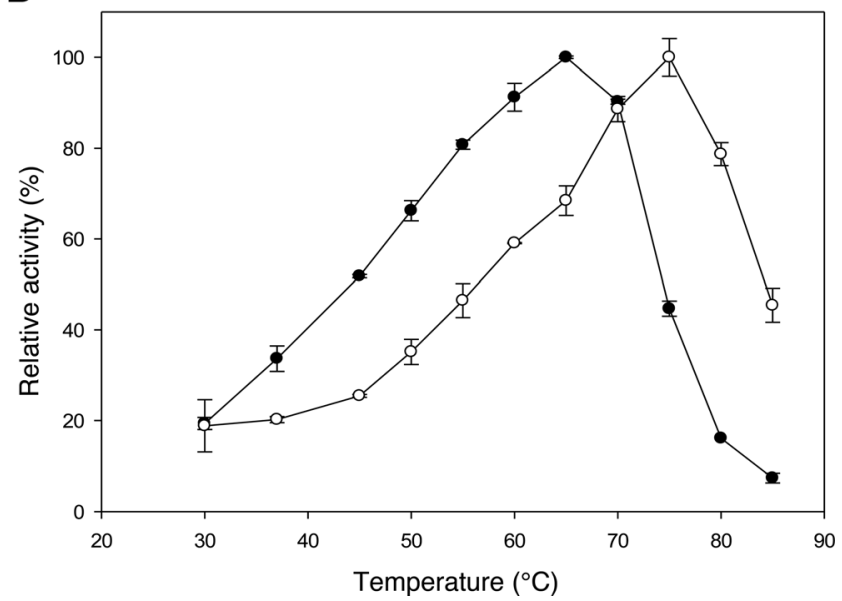

Fig. 1 Effect of $\mathrm{pH}$ and temperature on the $\beta$-galactosidase activity of $H o B G L A$. The dependency of $H o B G L A \beta$-galactosidase activity on $\mathrm{pH}$ (a) and temperature (b) optimum using $o \mathrm{NPGal}$ and D-lactose as substrates. Symbols: (black circle) oNPGal and (white circle) D-lactose. The standard $\beta$-galactosidase assay was used, and the activity analyzed using $o$ NPGal in the $\mathrm{pH}$ range 4-10 using Briton-Robinson buffer (see Materials and methods for details). The temperature optima for activity with lactose and $o \mathrm{NPGal}$ as substrates were determined in the temperature range $30-85^{\circ} \mathrm{C}$, in $20 \mathrm{mM}$ HEPES and $150 \mathrm{mM} \mathrm{NaCl}(\mathrm{pH} 7.0)$

product was identified as $\beta$-D-Galp-(1 $\rightarrow 6)$-D-Lac, accounting for approximately $42 \%$ of the total GOS formed at maximum GOS yield. $\beta$-D-Gal $p$ - $(1 \rightarrow 3)$-D-Lac was identified as the second predominant transferase product at the maximum total GOS yield point, contributing approximately $18 \%$ of the total GOS formed. Other identified products that are formed to lesser amounts include $\beta$-D-Gal $p$ - $(1 \rightarrow 3)-G l c, \beta$-D-Gal $p$ - $(1 \rightarrow$ $3)$-Gal, $\beta$-D-Gal $p$-( $1 \rightarrow 6)$-Gal, $\beta$-D-Gal $p$-( $1 \rightarrow 6)$-Glc, and $\beta$-DGal $p-(1 \rightarrow 4)-$ Lac.

\section{Overall structure of HoBGLA}

Data collection and refinement statistics for the three wildtype HoBGLA models are presented in Table S1. As reported previously (Kori et al. 2011), the overall structure of the 451-
Fig. 2 Transglycosylation products from lactose hydrolysis. a Hydrolysis of lactose catalyzed by HoBGLA as analyzed by TLC on preactivated silica plates (eluent: $n$-butanol- $n$-propanol-ethanol-water $=$ 2:3:3:2). The reaction was carried out at $70{ }^{\circ} \mathrm{C}$ with an initial lactose concentration of $205 \mathrm{~g} / \mathrm{L}$ in $20 \mathrm{mM}$ HEPES and $150 \mathrm{mM} \mathrm{NaCl}$ (pH 7.0), containing $1 \mathrm{mM} \mathrm{MgCl}{ }_{2}$ and $12.0 \mathrm{U}_{o \mathrm{NP}} / \mathrm{mL}$ of $H o B G L A$. Samples were withdrawn at regular time intervals during the reaction. A commercially available GOS preparation, Elix'or (Friesland Foods Domo), was used for comparison. b Time-course of total GOS production catalyzed by wildtype $H o B G L A$. The reaction was performed at $70{ }^{\circ} \mathrm{C}, 300 \mathrm{rpm}$ at various initial lactose concentrations $(200,300$, and $400 \mathrm{~g} / \mathrm{L})$ in HEPES and $150 \mathrm{mM} \mathrm{NaCl}$ (pH 7.0), containing $1 \mathrm{mM} \mathrm{MgCl}_{2}$ using $12.0 \mathrm{U}_{o \mathrm{NP}} / \mathrm{mL}$. Symbols: (black circle) $200 \mathrm{~g} / \mathrm{L}$ initial lactose concentration; (white circle) $300 \mathrm{~g} / \mathrm{L}$ initial lactose concentration; and (black triangle) $400 \mathrm{~g} /$ $\mathrm{L}$ initial lactose concentration. c GOS yield (\% of total mass) at different lactose conversion catalyzed by wild-type $H o B G L A$. The reaction was performed at $70^{\circ} \mathrm{C}, 300 \mathrm{rpm}$ at various initial lactose concentrations (200, 300 , and $400 \mathrm{~g} / \mathrm{L}$ ) in HEPES and $150 \mathrm{mM} \mathrm{NaCl}(\mathrm{pH} \mathrm{7.0)}$ ), containing $1 \mathrm{mM} \mathrm{MgCl}_{2}$ using $12.0 \mathrm{U}_{\text {oNP }} / \mathrm{mL}$. Symbols: (black circle) $200 \mathrm{~g} / \mathrm{L}$ initial lactose concentration; (white circle) $300 \mathrm{~g} / \mathrm{L}$ initial lactose concentration; and (black triangle) $400 \mathrm{~g} / \mathrm{L}$ initial lactose concentration. d Individual GOS components produced by the transgalactosylation reaction of wildtype HoBGLA using lactose as substrate. Symbols: (white diamond) D-

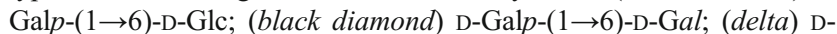
Gal $p-(1 \rightarrow 3)-\mathrm{D}-\mathrm{G} a l$; (black triangle) $\mathrm{D}-\mathrm{Gal} p-(1 \rightarrow 3)-\mathrm{D}-\mathrm{G} l c$; (white square) D-Gal $p-(1 \rightarrow 3)-\mathrm{D}-L a c$; (black square) D-Gal $p-(1 \rightarrow 4)-\mathrm{D}-L a c$; (white circle)

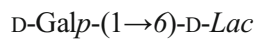

residue large $H o$ BGLA displays the typical $(\beta / \alpha)_{8}$ TIM-barrel fold adopted by retaining GH1 enzymes. For all three models, the residues Met1-Ala2-Lys3 and the three C-terminal residues E449-Ala450-Asn451 are missing due to local disorder and lack of interpretable electron density at the N- and Cterminus, respectively. Here, we focus the structural description on the details of ligand binding in the active site.

\section{Structure of the HoBGLA-thiocellobiose complex}

The crystal structure of $H o B G L A$ in complex with thiocellobiose, $H o B G L A-T C B$, was determined at $1.85 \AA$ resolution, and shows well-defined electron density for the TCB ligand (Fig. 3a). To date, only one TCB complex of a GH1 glycoside hydrolase is reported, namely that of $\beta$-glucosidase B from Paenibacillus polymyxa (PpBGLB; PDB code 2O9R; Isorna et al. 2007). Considering the overall similarity of the active site in $H o B G L A$ and $P p B G L B$, the striking difference in TCB binding was unexpected (Fig. $3 b$ ). In PpBGLB, TCB binds with the nonreducing-end glucosyl unit in subsite -1 and the reducing-end glucosyl in +1 , similar to what is expected based on BGL complexes of longer cellooligomers, e.g., rice $\beta$ glucosidase BGlu1 (PDB code 3F5K; Chuenchor et al. 2011). In HoBGLA, however, the TCB molecules folds into an unusual conformation to place the reducing end $\mathrm{O} 1$ atom within short hydrogen-bonding distance of the catalytic nucleophile Glu354 Oع2 atom (Table S2). The reason is most likely a bound PEG molecule occupying part of the +1 subsite, $+2,+$ 3 , and part of +4 (number of subsites inferred from PDB code 
A

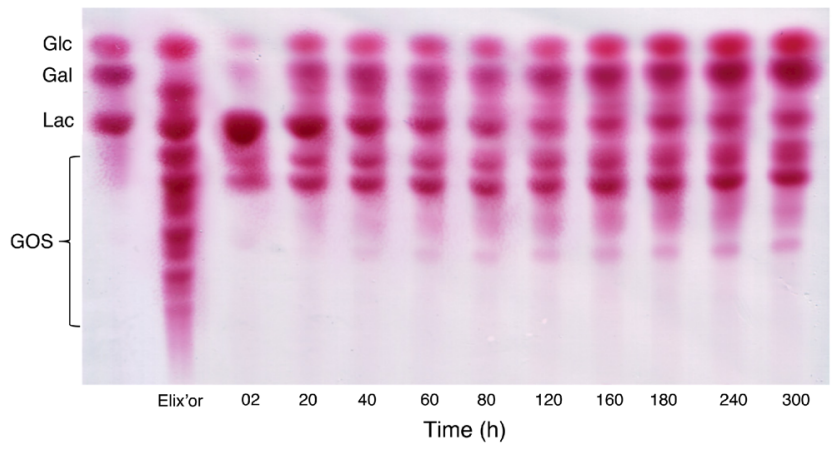

B

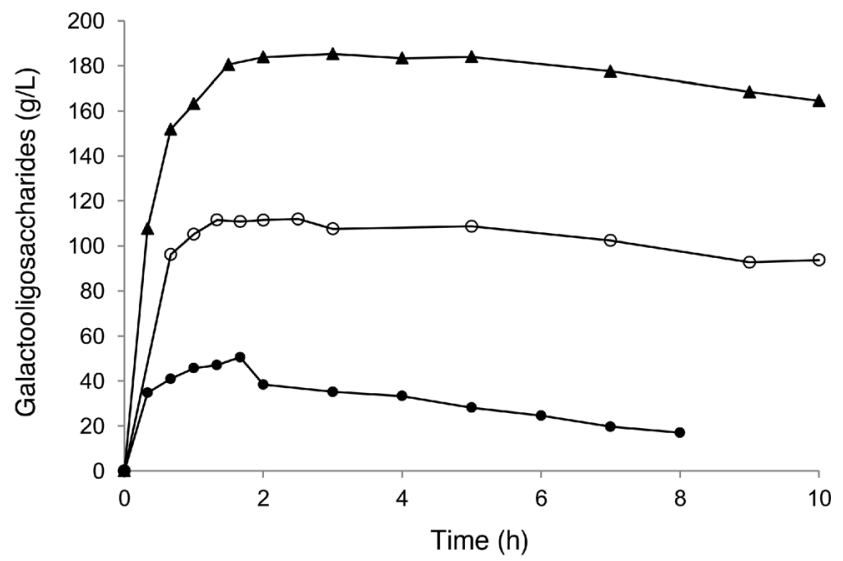

C

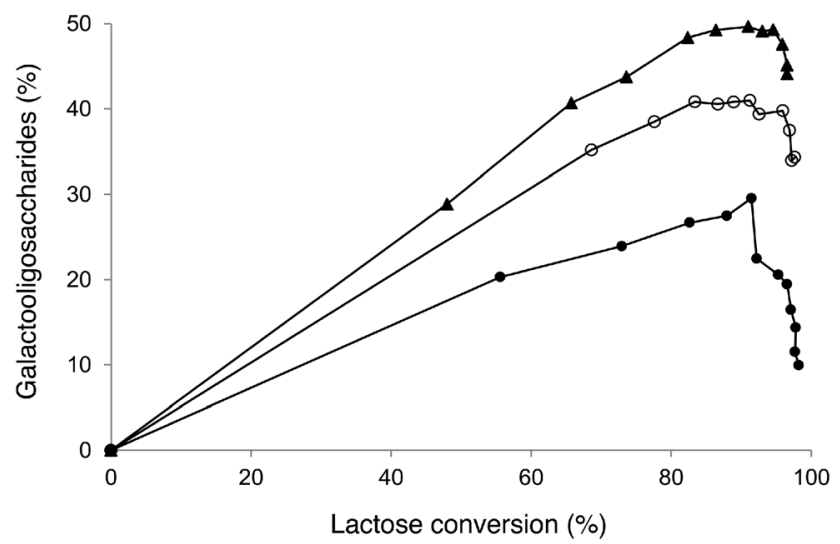

D

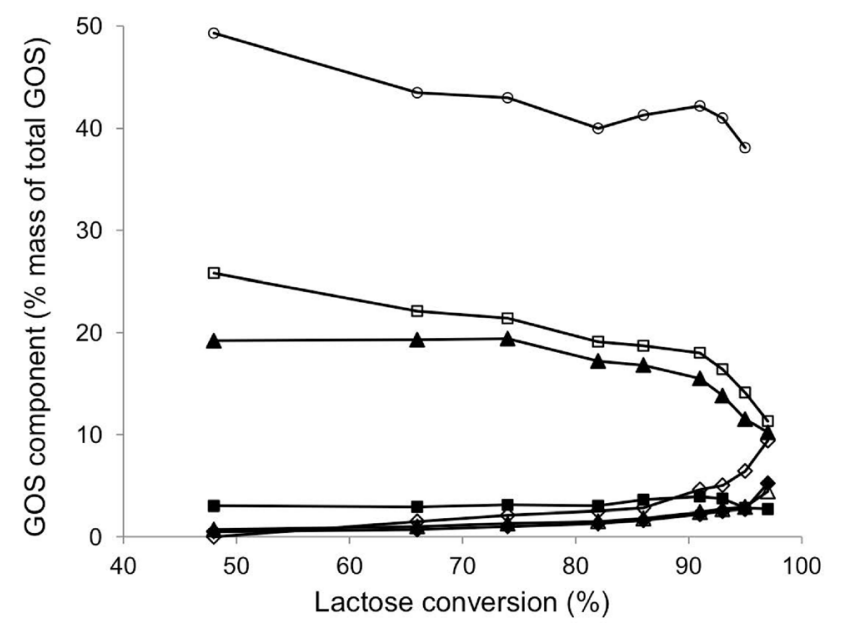


3F5K), which competes with TCB for the +1 site and effectively forces it to adopt a different conformation. The binding of the PEG molecule traces out the better part of the substratebinding cleft showing that HoBGLA can indeed accommodate extended molecules, which is relevant for synthesis of longer GOS products.

In rice BGlu1, an extended loop comprising residues 322335 delineates the far "plus end" of the binding cleft and its tip folds to form one side of the substrate-binding cleft. The corresponding loop in HoBGLA is considerably shorter (residues 303-308), which provides more space in this region of the cleft. Consequently, the PEG molecule is allowed to bind differently in +4 than the corresponding glucosyl unit in cellopentaose bound to BGlu1 (Fig. S3). We predict that an oligosaccharide longer than four sugar units, i.e., binding beyond subsite +3 , could be bound to HoBGLA either as observed for the cellopentaose in BGlu1, or possibly, as observed for PEG in the TCB complex. Based on the binding of PEG to $H o B G L A$, and the $3 \mathrm{~F} 5 \mathrm{~K}$ structure, the following residues may be part of the putative binding sites +3 and +4 : Val314, Leu242, Tyr245, Phe177, Asn308, Asp307, and Glu313.

Thus, despite this TCB binding mode being an obvious artifact, the importance of the complex is twofold: firstly, it allows us to verify an extended substrate-binding region where longer transglycosylation products may bind; and secondly, it provides additional information regarding possible conformers for TCB, which is valuable considering that only four TCB-bound structures exist in the Protein Data Bank, neither of which displays this conformation.

\section{Structure of the covalent HoBGLA-2FGlc complex}

The attachment of an electronegative fluorine atom close to the reacting carbon atom serves to destabilize the oxocarbenium ion-like transition state and reduces the reaction rates in both the glycosylation and deglycosylation steps of the retaining reaction. To allow accumulation and trapping of the fluoroglucopyranosyl-nucleophile intermediate by making the deglycosylation step rate-limiting, a good leaving group (a highly reactive aglycon) is attached to the substrate to selectively slow down the breakdown of the intermediate relative to the rate of formation (Withers et al. 1987, 1988).

The $2.0 \AA$ structure of the 2-deoxy-2fluoroglucopyranosyl-HoBGLA intermediate was obtained by soaking crystals with only $2 F$ Glc and not with an activated compound such as 2,4-dinitrophenyl 2-deoxy-2-fluoro- $\beta$-Dglucoside (DNP- $2 F \mathrm{Glc}$ ) or 2-deoxy-2-fluoro- $\beta$-D-glucosyl fluoride. Nonetheless, the catalytic nucleophile appears to be labeled by $2 F$ Glc (Fig. 3c; Table S2) in both molecules of the asymmetric unit with covalent-bond (Glu354 Oع1-2FGlc C1) distances of 1.60 and $1.58 \AA$, respectively. It is likely that the covalent complex is a result of reverse hydrolysis. Based on the elongated bond distance compared with that expected for a stable covalent intermediate (about 1.35 to $1.45 \AA$ ), the structure may reflect a somewhat destabilized covalent complex. However, there are no obvious alternative orientations of either the $2 F$ Glc molecule or the Glu354 side chain. It is also clear from the electron density that the equatorial O1 hydroxyl group for $2 F \mathrm{Flc}$ has been removed. The $2 F$ Glc-labeled nucleophile complex of $H o B G L A$ is very similar to that of other 2FGlc complexes of wild-type GH1 BGLs (PDB codes: 3PTM, 3AIR, 3AIW, 3GNR, 2RGM, 2JIE, 1UWS, 1OIN, and $1 \mathrm{~W} 4 \mathrm{I}$ ), of which the $\beta$-glucosidase complexes from rice (PDB code 3PTM), wheat (PDB code 3AIR), and rye (PDB code 3 AIW) are nearly identical (Fig. 3d).

In subsite -1 of the active site, the catalytic residues Glu354 (nucleophile) and Glu166 (acid/base catalyst) are situated near Glu408. The Glu408 $\mathrm{O} \varepsilon 1$ and $\mathrm{O} \varepsilon 2$ oxygen atoms participate in substrate binding by offering two hydrogen bonds to $\mathrm{O} 4$ in $2 F G l c$. Considering that a glutamine can provide the same hydrogen bonds, the 15 -fold decrease in $k_{\text {cat,app }}$ for the E408Q mutant is probably due to perturbation of the electrostatic environment of the active site. Trp401 provide hydrophobic stacking with the glucosyl residue in this subsite and additional protein-sugar hydrogen bonds are formed by Gln20, Trp409, His121, Asn165, and Glu354 (Fig. 3c; Table S2).

The Cremer-Pople puckering parameters for $2 F \mathrm{Glc}$ were analyzed using the Cremer-Pople parameter calculator (http:// www.ric.hi-ho.ne.jp/asfushi/). The puckering parameters $[\varphi=$ $\left.103.4^{\circ}, \theta=7.0^{\circ}, \mathrm{Q}=0.64\right]$ are consistent with a ${ }^{4} C_{1}$ chair with a slight distortion in the direction of a ${ }^{2,5} B$ boat ${ }^{5} S_{1}$ skew boat. For comparison, puckering parameters for the three structurally most similar covalent $2 F$ Glc complexes are: 3PTM $\left(\varphi=195.0^{\circ}, \theta=3.7^{\circ}, \mathrm{Q}=0.60\right) ; 3 \mathrm{AIR}\left(\varphi=255.1^{\circ}, \theta=\right.$ $\left.13.2^{\circ}, \mathrm{Q}=0.56\right)$; and $3 \mathrm{AIW}\left(\varphi=36.2^{\circ}, \theta=4.4^{\circ}, \mathrm{Q}=0.65\right)$.

\section{Structure of the HoBGLA-glucose complex}

The crystal structure of $H o$ BGLA in complex with glucose, representing the post-hydrolysis state, was determined and refined at $1.80 \AA$ resolution (Fig. 3e; Table S2). Of the many previously reported crystal structures of GH1 BGLs in complex with glucose, that of a BGL from an uncultured bacterium (PDB codes 4HZ7 and 4HZ8; Nam et al. 2010) is the most similar with respect to structural details of glucose binding (Fig. 3f). The glucose product interacts intimately with protein to allow all its exocyclic hydroxyl groups to be positioned within hydrogen-bonding distance to the primary shell of protein side chains in subsite -1 . Despite being noncovalently bound, the protein interactions made by the glucose molecule are identical to those observed for the covalently linked $2 F$ Glc, the exception being that the acid/base catalyst Glu166 forms two hydrogen bonds to the Glc O1 hydroxyl group (Fig. 3e; Table S2). 

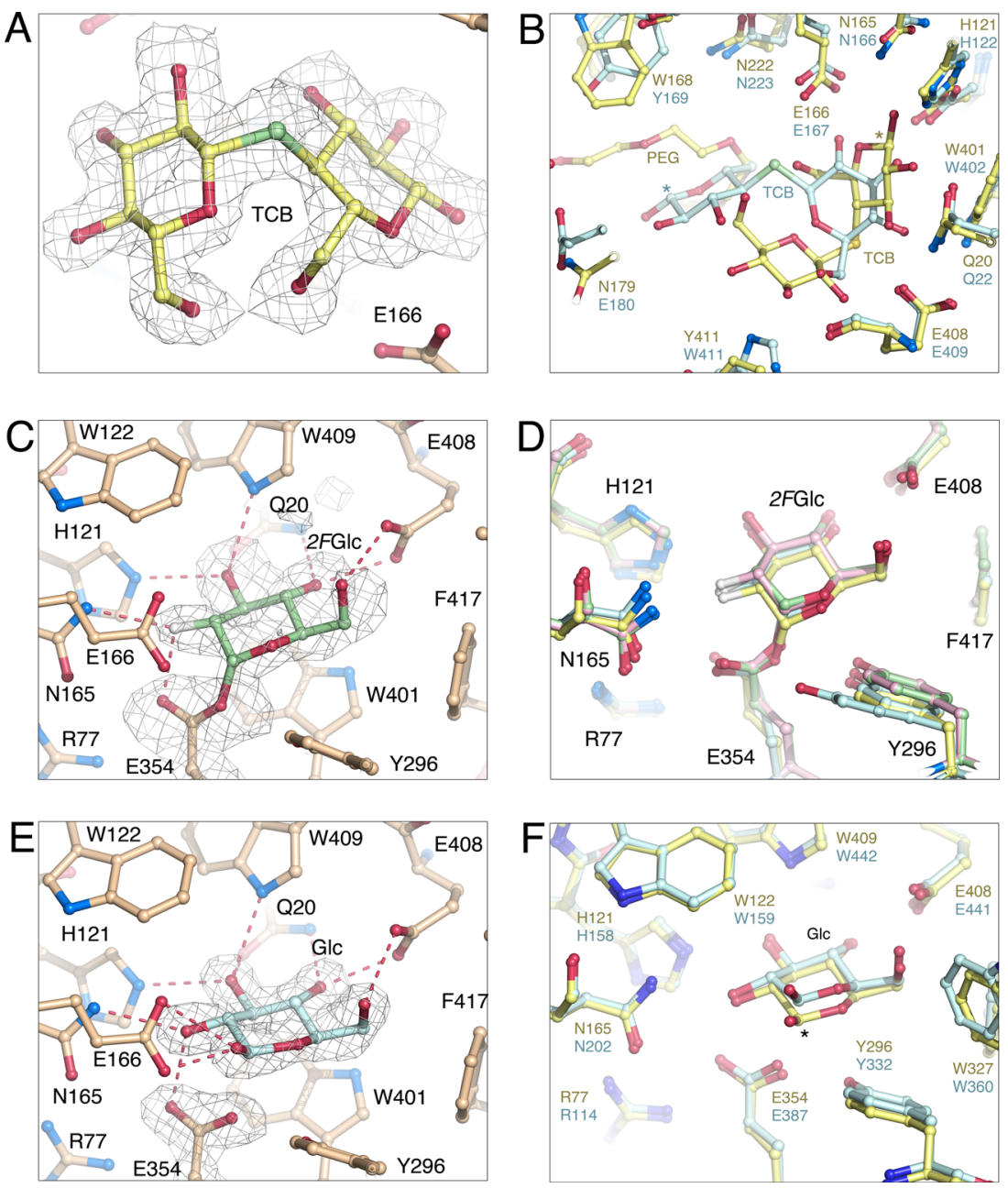

Fig. 3 Structural details of ligand binding. a Binding of thiocellobiose to $H o$ BGLA with superimposed $2 F_{\mathrm{o}}-F_{\mathrm{c}}$ electron density. b Overlay of the HoBGLA-TCB complex (yellow) with $P$. polymyxa $\beta$-glucosidase B (PDB code 2O9R; Isorna et al. 2007) in blue color. The asterisk denotes the $\mathrm{C} 1$ position of the reducing end glucosyl unit. $\mathbf{c}$ Binding of 2-deoxy-2fluoro-D-glucose to $H o B G L A$ with superimposed positive difference omit Fourier map contoured at $2.5 \sigma$. d Overlay of the HoBGLA- $2 F$ Glc complex (yellow) with those of rice Os4BGlu12 (blue; PDB code 3PTM;

The Cremer-Pople puckering parameters for glucose bound to $\mathrm{HoBGLA}$ are $\left(\varphi=237.9^{\circ}, \theta=15.7^{\circ}, \mathrm{Q}=0.57\right)$, consistent with a ${ }^{4} C_{1}$ chair somewhat distorted toward a ${ }^{1,4} B$ boat. The puckering parameters for the structurally most similar glucose complex are $4 \mathrm{HZ} 8\left(\varphi=270.8^{\circ}, \theta=18.4^{\circ}, \mathrm{Q}=0.60\right)$ where the glucose molecule is distorted from the relaxed ${ }^{4} C_{1}$ chair in the direction of a ${ }^{1} S_{5}$ skew boat.

\section{Discussion}

A number of retaining GH1 BGLs are capable of catalyzing both hydrolysis and transglycosylation reactions; however, a little is known about the factors that determine the balance

Sansenya et al. 2011), wheat $\beta$-glucosidase (green; PDB code 3AIR; Sue et al. 2011), and rye $\beta$-glucosidase (pink; PDB code 3AIW; Sue et al. 2011). e Binding of $\beta$-D-glucose to HoBGLA with superimposed positive difference omit Fourier map contoured at $5 \sigma$. f Overlay of the HoBGLAGlc complex (yellow) with a $\beta$-glucosidase $B$ from an uncultured bacterium (PDB code 4HZ8; Nam et al. 2010) in blue color. The asterisk denotes the $\mathrm{C} 1$ position in the glucosyl unit. The pictures were made using the program PyMOL (De Lano 2002)

between the two activities (Teze et al. 2014). Owing to the practical applications of GOS production from hydrolysis of milk lactose, several attempts have been made to engineer BGLs towards sufficient transglycosylation activity while keeping the hydrolysis activity at a minimum, or towards a higher transglycosylation-to-hydrolysis ratio compared with the wild type through mutations targeting either the aglycon or glycon binding site of the enzyme (Hansson et al. 2001; Feng et al. 2005).

The GH1 $\beta$-glucosidase HoBGLA is produced by the thermophilic bacterium Halothermothrix orenii, a bacterium that grows optimally at $60{ }^{\circ} \mathrm{C}$ with $\mathrm{NaCl}$ concentrations ranging between 5 and $10 \%$ (Cayol et al. 1994). In this study, we show that $H o$ BGLA displays promising characteristics for GOS production compared with GOS-producing BGLs 
reported to date. HoBGLA hydrolyzes both $\beta$-glucosides such as cellobiose, and $\beta$-galactosidases such as lactose. Based on our kinetic analysis, $\beta$-glucosides are the preferred substrates, and hence, the name $\beta$-glucosidase can be used for the enzyme. HoBGLA is a nonspecific BGL with mixed activities for different substrates, and shows prominent activity with various galactosides. The apparent Michaelis constant of $\mathrm{Ho}-$ BGLA for lactose is relatively high compared to the values reported for some commonly used commercial enzymes (A. oryzae, 36-180 mM; A. niger, 54-99 mM; K. fragilis, 15-52 mM; and K. lactis, $35 \mathrm{mM}$; Jurado et al. 2002; de Roos 2004). Most of these commercial enzymes are from mesophilic sources, whereas HoBGLA is thermophilic and the kinetic constants were measured at $65^{\circ} \mathrm{C}$. It is known that the apparent strength of substrate binding decreases with increasing temperature. A clear disadvantage of high $K_{\mathrm{m} \text {,Lac }}$ values is that complete substrate conversion in a single-stage continuous tank reactors is difficult to achieve. Nonetheless, a number of favorable characteristics make HoBGLA an attractive biocatalyst for lactose conversion: (i) $\mathrm{pH}$ optimum of about 6 for lactose hydrolysis; (ii) the broad optimal stability over the $\mathrm{pH}$ range of 4.5 to 7.5 ; (iii) a temperature optimum in the range $65-70{ }^{\circ} \mathrm{C}$; and (iv) its thermostability within the aforementioned temperature range.

A major drawback of using mesophilic biocatalysts in industrial processes is the risk of microbial contamination. Working under sterile conditions requires special equipment
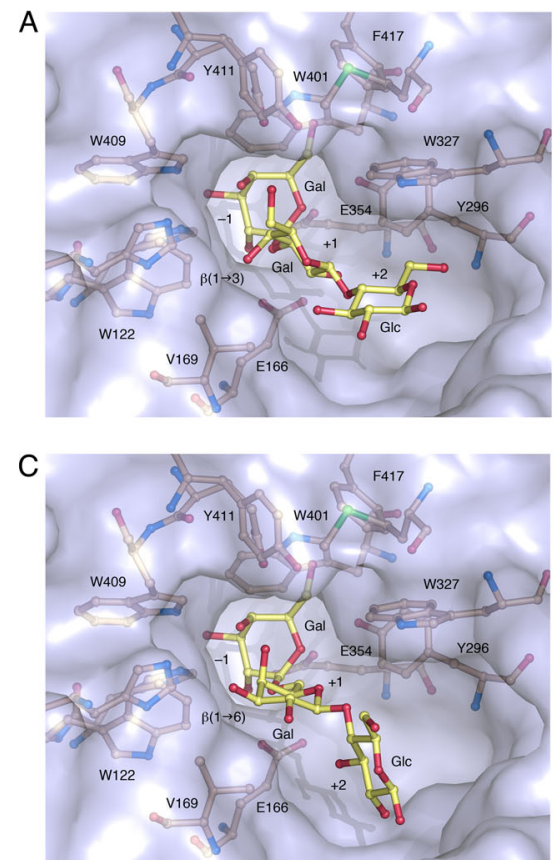

Fig. 4 Theoretical modeling of the major trisaccharide GOS products 3GALA and 6GALA. a Overview of modeled 3GALA in HoBGLA in the substrate-binding cleft of HoBGLA, and $\mathbf{b}$ details of predicted protein-sugar interactions in subsites $-1,+1$, and +2 . $\mathbf{c}$ Overview of 6GALA binding and (cus) details of predicted protein-sugar interactions in subsites $-1,+1$, and +2 . The ${ }^{1,4} B$ boat conformation of the galactosyl and extra process steps leading to additional costs. Apart from the microbial quality of the raw materials, reaction temperature and conversion rate are important parameters to overcome these problems. HoBGLA is thus a promising candidate for lactose hydrolysis and GOS formation at $65-70{ }^{\circ} \mathrm{C}$. The highest total GOS yield of approximately $50 \%$ was obtained in discontinuous conversion reactions with an initial lactose concentration of $400 \mathrm{~g} / \mathrm{L}$. This value lays in the upper range of enzymatic GOS productivity reported so far (Park and Oh 2010). The major products are $\beta$-D-Galp- $(1 \rightarrow 6)-\mathrm{D}-\mathrm{Lac}$ and $\beta$-D-Gal $p-(1 \rightarrow 3)$-D-Lac, indicating that lactose is a far better galactosyl acceptor than glucose and galactose, and that $\mathrm{Ho}$ BGLA has a high specificity for forming $\beta-1 \rightarrow 6$ and $\beta-1 \rightarrow 3$ linkages.

Although the glucose inhibition profile of HoBGLA has not been investigated specifically, the achievement of $>97 \%$ lactose conversion within a short period of time indicates high tolerance to product inhibition. Based on the comparably good thermal stability and the high transgalactosylation activity, this enzyme should be useful for the efficient hydrolysis of lactose in milk and whey, as well as for the production of lactose-derived oligosaccharides. In addition, this non-specific BGL can be used in enzyme systems for degradation of cellulose or cellodextrins during growth on lignocellulose.

In order to investigate how well the major GOS products,

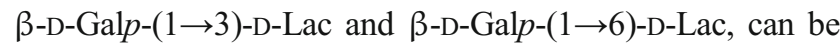

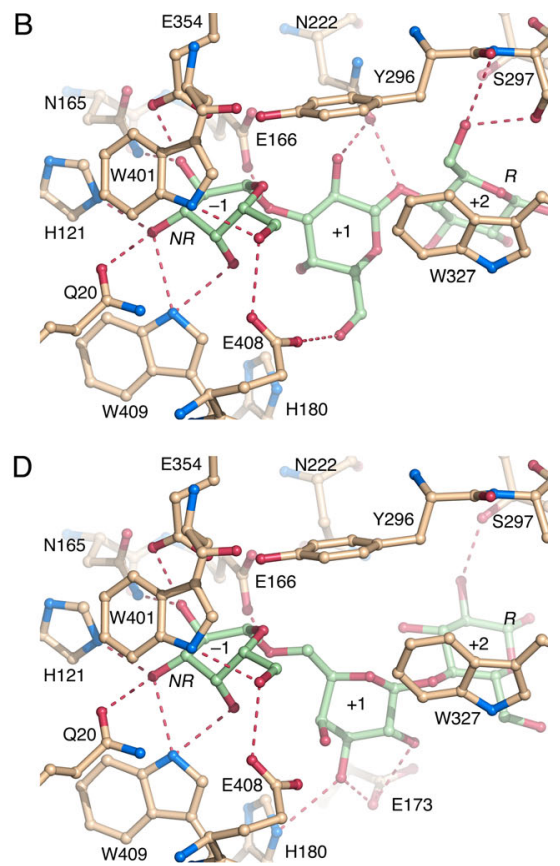

unit in subsite -1 for 3GALA and 6GALA was based on the glucose conformer observed in the cellopentaose complex of rice BGlu1 (PDB code 3F5K; Chuenchor et al. 2011). The subsites are denoted $-1,+1$, and +2 , and the reducing and non-reducing end sugar units are marked by $\mathrm{R}$ and NR, respectively. Hydrogen bonds are shown as dashed red lines. The protein-sugar interactions are also listed in Table S3 
accommodated in the HoBGLA substrate-binding cleft, we modeled the two trisaccharides 3GALA and 6GALA manually. To guide modeling, the HoBGLA complexes and the cellopentaose (G5) complex of rice BGlu1 was analyzed in detail (PDB code 3F5K; Chuenchor et al. 2011). The BGlu1G5 complex shows the non-reducing end glucosyl unit in subsite -1 adopting a boat whereas the glucosyl units in subsites +1 to +4 adopt the relaxed ${ }^{4} C_{1}$ chair conformation. The two GOS trisaccharides were modeled to mimic closely the glucosyl-binding modes in subsites -1 and +1 of BGlu1, but with a non-reducing end galactose unit of 3GALA and 6GALA in subsite -1 . In 3GALA, the skew-boat galactose residue in -1 is linked at $\mathrm{C} 1$ to $\mathrm{C} 3$ of the galactosyl unit (in subsite + 1) of lactose by a $\beta-1,3$-glycosidic bond (Fig. $4 a, b)$. In 6GALA, the linkage between galactose and lactose is instead a $\beta-1,6$-glycosidic bond between $\mathrm{C} 1$ of the skew-boat galactose (subsite -1 ) and the exocyclic C6 carbon of the +1 subsite galactosyl unit in lactose (Fig. 4c, d). The modeling suggests that both 3GALA and 6GALA are well accommodated in the binding cleft of $H o B G L A$ such that the non-reducing end galactosyl unit is bound in subsite -1 , the second galactosyl unit in subsite +1 and the reducing-end glucosyl unit in subsite +2 . These models provide an initial structural framework for further design of mutants with improved transgalactosylation and GOS production; however, the precise structural determinants will depend on which GOS is to be synthesized. There are several examples of engineering of BGLs to achieve higher transglycosylation efficiency for certain products. In the case of HoBGLA, the inherently high stability and transgalactosylation activity provide an ideal starting point for enzyme engineering towards improved 3GALA/6GALA yields or other GOSs.

Examples of BGLs that have been engineered towards improved GOS yield are from the hyperthermophilic archaea Pyrococcus furiosus (CelB) and Sulfolobus solfataricus P2 (LacS). For CelB, the mutant F426Y showed an oligosaccharide yield of $45 \%(w / w)$ compared to $40 \%$ for the wild type (Hansson et al. 2001). This mutant had improved affinity for galactosidases as judged by a decrease in $K_{\mathrm{m}}$ from 2.3 to $0.9 \mathrm{mM}$ (Kaper et al. 2000). In the case of LacS, two single amino-acid replacements F359Q and F441Y (F426Y in CelB) resulted in an increase in GOS yield from $51 \%$ for the wild type to 58 and $62 \%$, respectively (Wu et al. 2013). Unfortunately, no data were reported for the double mutant. Although the precise mutations may not be useful for improving the GOS yield by $H o B G L A$, they can provide guidance on suitable future engineering strategies for improved GOS yields from HoBGLA transgalactosylation.
Acknowledgments The authors thank the beamline staff at ESRF beamlines ID23-2 and ID14-4 for support during data collection. CD and TCT were supported by grants from the Swedish Research Council VR (VR grants 2008-4045 and 2011-5768). THN was supported from the Austrian Science Fund (FWF grant P24868-B22), and MI was supported by a 'Technologiestipendium Südostasien in the frame of the ASEA-Uninet granted by the OeAD-Austrian Agency for International Cooperation in Education \& Research' financed by the Austrian Federal Ministry of Science, Research and Economy. LK was supported by a Griffith University Post-graduate Research Scholarship (GUPRS) and Griffith University International Post-graduate Research Scholarship (GUIPRS) awards, Australia. This work was facilitated by the Protein Science Facility at Karolinska Institutet/SciLifeLab (http://psf.ki.se). The authors have no conflict of interests to declare.

Open Access This article is distributed under the terms of the Creative Commons Attribution License which permits any use, distribution, and reproduction in any medium, provided the original author(s) and the source are credited.

\section{References}

Adams PD, Afonine PV, Bunkóczi G, Chen VB, Davis IW, Echols N, Headd JJ, Hung LW, Kapral GJ, Grosse-Kunstleve RW, McCoy AJ, Moriarty NW, Oeffner R, Read RJ, Richardson DC, Richardson JS, Terwilliger TC, Zwart PH (2010) PHENIX: a comprehensive Python-based system for macromolecular structure solution. Acta Crystallogr D Biol Crystallogr 66:213-221

Bhatia Y, Mishra S, Bisaria VS (2002) Microbial $\beta$-glucosidases: Cloning, properties, and applications. Crit Rev Biotechnol 22:375407

Bruins ME, Van Hellemond EW, Janssen AM, Boom RM (2003) Maillard reactions and increased enzyme inactivation during oligosaccharide synthesis by a hyperthermophilic glycosidase. Biotechnol Bioeng 81:546-552

Cantarel BL, Coutinho PM, Rancurel C, Bernard T, Lombard V, Henrissat B (2009) The carbohydrate-active EnZymes database (CAZy): an expert resource for glycogenomics. Nucleic Acids Res 37:233-238

Cayol I, Olliver B, Patel BKC, Prensier G, Guezennec J, Garcia JL (1994) Isolation and characterization of Halothermothrix orenii gen. nov., sp. nov., a halophilic, thermophilic, fermentative, strictly anaerobic bacterium. Int J Syst Bacteriol 44:534-540

Chuenchor W, Pengthaisong S, Robinsin RC, Yuvaniyama J, Svasti J, Cairns JRK (2011) The structural basis of oligosaccharide binding by rice BGlu1 beta-glucosidase. J Struc Biol 173:169-179

De Lano W (2002) The PyMOL molecular graphics system. Delando Scientific, San Carlos, CA

De Roode BM, Franssen ACR, van der Padt A, Boom RM (2003) Perspectives for the industrial enzymatic production of glycosides. Biotechnol Prog 19:1391-1402

De Roos A (2004) Industrial enzymes: enzymes in dairy applications. Enzymes in Industry, Vol. 2 (Aehle W, ed.), p. 144. Wiley-VCH, Weinheim.

Doyle SA (2005) High through put cloning for proteomics research. Meth Mol Biol 310:107-113

Emsley P, Cowtan K (2004) Coot: Model-building tools for molecular graphics. Acta Crystallogr D Biol Crystallogr 60:2126-2132

Feng HY, Drone J, Hoffmann L, Tran V, Tellier C, Rabiller C, Dion M (2005) Converting a $\beta$-glycosidase into a $\beta$-transglycosidase by directed evolution. J Biol Chem 280:37088-37097 
Hansson T, Kaper T, van der Oost J, de Vos WM, Adlercreutz P (2001) Improved oligosaccharide synthesis by protein engineering of $\beta$ glucosidase CelB from hyperthermophilic Pyrococcus furiosus. Biotechnol Bioeng 73:203-210

Iqbal S, Nguyen TH, Nguyen HA, Nguyen TT, Maischberger T, Kittl R, Haltrich D (2011) Characterization of a heterodimeric GH2 $\beta$ galactosidase from Lactobacillus sakei Lb790 and formation of prebiotic galacto-oligosaccharides. J Agric Food Chem 59:3803-3811

Isorna P, Polaina J, Latorre-Garcia L, Canada FJ, Gonzales B, SanzAparicio J (2007) Crystal structures of Paenibacillus polymyxa $\beta$ glucosidase B complexes reveal the molecular basis of substrate specificity and give new insights into the catalytic machinery of family 1 glycosidases. J Mol Biol 371:1204-1218

Jones TA, Zou JY, Cowan SW, Kjeldgaard M (1991) Improved methods for building protein models in electron density maps and the location of errors in these models. Acta Crystallogr A 47:110-119

Jørgensen F, Hansen OC, Stougaard P (2001) High-efficiency synthesis of oligosaccharides with a truncated $\beta$-galactosidase from Bifidobacterium bifidum. Appl Microbiol Biotechnol 57:647-652

Jurado E, Camacho F, Luzón G, Vicaria JM (2002) A new kinetic model proposed for enzymatic hydrolysis of lactose by a $\beta$-galactosidase from Kluyveromyces fragilis. Enz Microb Technol 31:300-309

Kabsch W (1993) Automatic processing of rotation diffraction data from crystals of initially unknown symmetry and cell constants. J Appl Crystallogr 26:795-800

Kaper T, Lebbink JHG, Pouwels J, Kopp J, Schulz GE, van der Oost J, de Vos WM (2000) Comparative structural analysis and substrate specificity engineering of the hyperthermostable $\beta$-glucosidase CelB from Pyrococcus furiosus. Biochemistry 39:4963-4970

Kori L, Hofmann A, Patel BKC (2011) Expression, purification and preliminary crystallographic analysis of the recombinant betaglucosidase (BglA) from the halothermophile Halothermothrix orenii. Acta Crystallogr F Struct Biol Commun 67:111-113

Kunst A, Draeger B, Ziegernhorn J (1988) Colorimetric methods with glucose oxidase and peroxidase. In: Bergmeyer HU, Bergmeyer J, Grassl M (eds) Methods of enzymatic analysis. VCH Publishers 1988, Weinheim, Germany, pp 178-185

Mavromatis K, Ivanova N, Anderson I, Lykidis A, Hooper SD, Sun H, Kunin V, Hugenholtz P, Patel B, Kyrpides NC (2009) Genome analysis of the anaerobic thermohalophilic bacterium Halothermothrix orenii. PLoS ONE 4:e4192

Mijts B, Patel BKC (2001) Random sequence analysis of genomic DNA of an anaerobic, thermophilic, halophilic bacterium, Halothermothrix orenii. Extremophiles 5:61-69

Nam KH, Sung MW, Hwang KY (2010) Structural insights into the substrate recognition of $\beta$-glucosidase. Biochem Biophys Res Commun 391:1131-1135

Nguyen TH, Splechtna B, Steinböck M, Kneifel W, Lettner HP, Kulbe KD, Haltrich D (2006) Purification and characterization of two novel $\beta$-galactosidases from Lactobacillus reuteri. J Agric Food Chem 54:4989-4998

Nguyen TH, Splechtna B, Krasteva S, Kneifel W, Kulbe KD, Divne C, Haltrich D (2007) Characterization and molecular cloning of a heterodimeric beta-galactosidase from the probiotic strain lactobacillus acidophilus R22. FEMS Microbiol Lett 269:146-144

Park AR, Oh DK (2010) Galacto-oligosaccharide production using microbial beta-galactosidase: Current state and perspectives. Appl Microbiol Biotechnol 85:1279-1286

Park T, Choi KW, Park CS, Lee CB, Kang HY, Shon KJ, Park JS, Cha J (2005) Substrate specificity and transglycosylation catalyzed by a thermostable beta-glucosidase from marine hyperthermophile Thermotoga neapolitana. Appl Microbiol Biotechnol 69:411-422

Placier G, Watzlawick H, Rabiller C, Mattes R (2009) Evolved $\beta$ galactosidases from Geobacillus stearothermophilus with improved transgalactosylation yield for galacto-oligosaccharide production. Appl Environ Microbiol 75:6312-6321

Sansenya S, Opassiri R, Kuaprasert B, Chen CJ, Cairns JR (2011) The crystal structure of rice (Oryza sativa L.) Os4BGlu12, an oligosaccharide and tuberonic acid glucoside-hydrolyzing ß-glucosidase with significant thioglucohydrolase activity. Arch Biochem Biophys 510:62-72

Savitsky P, Bray J, Cooper CDO, Marsden BD, Mahajan P, BurgessBrown NA, Gileadi O (2010) High-throughput production of human proteins for crystallization: the SGC experience. J Struct Biol 172:3-13

Smithers GW (2008) Whey and whey proteins-from 'gutter-to-gold'. Int Dairy J 18:695-704

Splechtna B, Nguyen TH, Steinböck M, Kulbe KD, Werner L, Haltrich D (2006) Production of prebiotic galacto-oligosaccharides from lactose using beta-galactosidases from Lactobacillus reuteri. J Agric Food Chem 54:4999-5006

Sue M, Nakamura C, Miyamoto T, Yajima S (2011) Active-site architecture of benzoxazinone-glucoside $\beta$-D-glucosidases in Triticeae. Plant Sci 180:268-275

Teze D, Hendrickx J, Czjzek M, Ropartz D, Sanejouand YH, Tran V, Tellier C, Dion M (2014) Semi-rational approach for converting a GH1 $\beta$-glucosidase into a $\beta$-transglucosidase. Prot Eng Des Sel 27: 13-19

Urrutia P, Rodriguez-Colinas B, Fernandez-Arrojo L, Ballesteros AO, Wilson L, Illanes A, Plou FJ (2013) Detailed analysis of galactooligosaccharides synthesis with $\beta$-galactosidase from Aspergillus oryzae. J Agric Food Chem 61:1081-1087

Vera C, Guerrero C, Conejeros R, Illanes A (2012) Synthesis of galactooligosaccharides by $\beta$-galactosidase from Aspergillus oryzae using partially dissolved and supersaturated solution of lactose. Enz Microbiol Technol 50:188-194

Withers SG, Street IP, Bird P, Dolphin DH (1987) 2-deoxy-2fluoroglucosides: a novel class of mechanism-based glucosidase inhibitors. J Am Chem Soc 109:7530-7531

Withers SG, Rupitz K, Street IP (1988) 2-deoxy-2-fluoro-D-glucosides: a new class of specific mechanism-based glycoside inhibitors. J Biol Chem 263:7929-7932

Wu Y, Yuan S, Chen S, Wu D, Chen J, Wu J (2013) Enhancing the production of galacto-oligosaccharides by mutagenesis of Sulfolobus solfataricus $\beta$-galactosidase. Food Chem 138: $1588-1595$ 